\title{
Group motivational intervention in overweight/ obese patients in primary prevention of cardiovascular disease in the primary healthcare area
}

Juan José Rodríguez Cristóbal ${ }^{1 *}$, Josefa Ma Panisello Royo ${ }^{2}$, Carlos Alonso-Villaverde Grote ${ }^{3}$, José Ma Pérez Santos ${ }^{1}$, Anna Muñoz Lloret ${ }^{4}$, Francisca Rodríguez Cortés ${ }^{5}$, Pere Travé Mercadé6, Francisca Benavides Márquez ${ }^{7}$, Pilar Martí de la Morena”, Ma José González Burgillos ${ }^{7}$, Marta Delclós Baulies ${ }^{1}$, Domingo Bleda Fernández ${ }^{1}$, Elida Quillama Torres ${ }^{8}$, representing the IMOAP group

\begin{abstract}
Background: The global mortality caused by cardiovascular disease increases with weight. The Framingham study showed that obesity is a cardiovascular risk factor independent of other risks such as type 2 diabetes mellitus, dyslipidemia and smoking. Moreover, the main problem in the management of weight-loss is its maintenance, if it is achieved. We have designed a study to determine whether a group motivational intervention, together with current clinical practice, is more efficient than the latter alone in the treatment of overweight and obesity, for initial weight loss and essentially to achieve maintenance of the weight achieved; and, secondly, to know if this intervention is more effective for reducing cardiovascular risk factors associated with overweight and obesity.

Methods: This 26-month follow up multi-centre trial, will include 1200 overweight/obese patients. Random assignment of the intervention by Basic Health Areas (BHA): two geographically separate groups have been created, one of which receives group motivational intervention (group intervention), delivered by a nurse trained by an expert phsychologist, in 32 group sessions, 1 to 12 fortnightly, and 13 to 32, monthly, on top of their standard program of diet, exercise, and the other (control group), receiving the usual follow up, with regular visits every 3 months.
\end{abstract}

Discussion: By addressing currently unanswered questions regarding the maintenance in weight loss in obesity/ overweight, upon the expected completion of participant follow-up in 2012, the IMOAP trial should document, for the first time, the benefits of a motivational intervention as a treatment tool of weight loss in a primary care setting.

Trial Registration: ClinicalTrials.gov Identifier: NCT01006213

\section{Background}

Introduction

Overweight and obesity are growing health problems throughout the industrialised world. If not controlled, it then will continue to contribute to the burden of nontransmitable diseases, which is increasing constantly. There is currently clear scientific evidence of the

\footnotetext{
* Correspondence: 21002jrc@comb.es

'Medicina, Area Básica Salud Florida Sud, Parc dels Ocellets, L'Hospitalet del
} Llobregat, Barcelona, Spain association of obesity and a large number of diseases and their manifestations, including: diabetes, hypertension, dyslipidemia, cardiovascular events and inflammatory markers such as plasma fibrinogen levels and Creactive protein $[1,2]$.

Overall mortality for cardiovascular causes increases with weight $[3,4]$ and, in the Framingham study, obesity was seen to be an independent risk factor for CVR regardless of other risk factors such as type 2 diabetes mellitus, dyslipidemia and smoking [5,6]; at the same 
time, overweight and obesity in adults significantly reduces life expectancy, in both women and men and smokers and non-smokers [7].

The prevalence of obesity is increasing continuously in developed countries, causing a serious public health problem. According to the SEEDO'2000 study, the figures for the prevalence of obesity in Spain (BMI>30) are $14.5 \%$ (13.3\% men and $15.7 \%$ women) while the overall overweight and obesity figure (BMI>25) is $53.5 \%[8,9]$.

When treating overweight and obesity, it is considered essential that diet should be included in a general programme, together with physical exercise, lifestyle changes and psychological support. However, although significant weight loss can be relatively easily achieved in the short term, its maintenance is very difficult to get, is for this that the research that could help these patients is so important. Drug treatment of obesity should not be used as an isolated therapy, but together with other basic therapies, such as diet, physical activity and psychological support. It should be prescribed to patients with BMI $>30$ or $>27$ if associated with co-morbidities, such as diabetes mellitus, arterial hypertension, dyslipidemia, sleep apnoea syndrome [10-13].

Weight loss is a healthcare need that leads to significant savings in the estimated cost of obesity and the diseases associated to it, both directly and indirectly, which amount to more than 2,500 million euros per annum, a figure that accounts for almost $7 \%$ of total healthcare costs $[14,15]$.

A variety of individual and group psychological therapies have been used in weight loss. In a study conducted in 20 primary healthcare centres in Great Britain, researchers evaluated the efficacy of a motivational interview to modify fat intake, physical activity and smoking in 883 patients at high risk of cardiovascular disease, obtaining a benefit in the intervention group [16].

Motivational intervention alone, in obese patients, has been shown to be effective, even in patients who only took a drug (sibutramine) for weight reduction [17]. But psychological interventions are particularly useful when combined with dietary and exercise strategies. In this review of 36 clinical studies, 26 were conducted in the United States, and only one in Spain, in diabetic obese patients $[18,19]$.

Other studies using motivational interviews have been shown to be effective for giving up smoking $[14,17]$, reducing alcohol intake $[20,21]$ and improved adherence to treatment strategies in diseases as common as arterial hypertension, diabetes mellitus and bronchial asthma [22].

When making lifestyle changes in the adult population, the interventional methods are complex, because individuals tend to cling to what is familiar, even though this may be putting their health at risk [23].

All changes involve some elements that evolve and others that remain stable. The aim is to help patients make them part of their lives without affecting what they feel is essential. However, it is important to help them perceive these as necessary and beneficial so that a series of changes they make will give them an awareness that their health depends on the type of habits they change, and that these can be taken as an exercise that will improve their health and well-being[21].

However, there are no studies in our primary care environment, in cardiovascular disease, that assess the efficacy of an intervention based on a group motivation interview about weight reduction in overweight and obese patients, and the maintenance of the weight achieved over time.

Studies are required among our patients to confirm the efficacy observed in other populations and the feasibility of the group motivation intervention in overweight and obese patients, with a view to suggesting its application in the primary care setting as a tool for dealing with this health problem.

For these reasons, a study has been proposed, to compare the efficacy of the healthcare professionals' usual practices, together with a motivational group intervention vs an isolated traditional intervention on weight loss and its maintenance in overweight and obese patients (IMOAP). The purpose of this report is to present the design of IMOAP trial.

\section{Methods}

\section{Study overview}

This study will be randomised, multi-centre interventional, in overweight and obese patients, with a followup of 26 months.

The overall goal of IMOAP study is to assess whether the efficacy of the healthcare professionals' usual practices, together with a motivational group intervention (delivered by a nurse trained by an expert psychologist), is more effective than an isolated traditional intervention on weight loss and its maintenance in overweight and obese patients. Furthermore, the study will evaluate whether this result has a positive impact on quality of life, changes in eating habits, and a reduction in the associated cardiovascular risk factors and overall cardiovascular risk.

Table 1 presents the timeline of the study. Protocol development, external review occurred over an initial 4-month period beginning in 2007.

A second phase had the purpose of the acceptance to participate of Basic Health Areas.

For this, the coordinators have contacted the Basic Health Areas, to explain the protocol and confirm their participation. After this period, it has been the distribution and randomisation into the study groups: Intervention/controls. For those BHA that will visit the intervention groups, it has been done the training of 
nursing staff and coordinating the teams, creating templates and study protocols.

The training of the nursing staff has consisted in a basic training strategy, initially aimed at nurses and focusing on group motivation for life-style changes in overweight and obese patients, because lack of motivation is a common cause of therapeutic failure. The training has consisted of a number of workshops where role play techniques have taken place to help assimilate the concepts taught. This workshop has been delivered at the BHA of the intervention group and written material delivered regarding the content. Secondly, a written guide has been created to standardise the information the nurses provide during the overweight and obesity check-up visits. The guide includes information about the disease, healthy habits and diet.

Randomization into the study began in first trimester 2008 , with a recruitment goal of 1,200 participants. The intervention and main trial recruitment will take place over 30 months with the patients in the intervention and control groups.

Finally, four months before the end of the project the final laboratory tests will be performed and the data collected for statistical analysis and reporting.

The first patient was entered on September 2008. The final visit for the last randomized participant is planned for the last trimester 2010, with final study reports expected in the first trimester of 2013.

\section{Selection of the study subjects}

The IMOPAP inclusion and exclusion criteria are presented in Table 2. These criteria have been established to identify a trial population with overweight and obesity, and with sufficient statistical power with the proposed sample size. They will be included sequentially, from the beginning of the study. To avoid possible bias in the selection of patients, and not overburden the nursing staff, patient recruitment and follow up will be rolled out in stages during the first six months of the study to the first two patients who meet the study inclusion requirements and who present none of the exclusion criteria. This will carry out superior quality control, using smaller sample size than would be possible if we randomised the patients. The institutional review Ethics Committee of Jordi Gol i Gurina Foundation in Barcelona approved the conduct of the study. In addition, the study has been done in compliance with the Helsinki Declaration. Each IMOAP participant has provided written informed consent using procedures reviewed and approved by the EECC review board.

\section{Measurements}

A wide range of interview, physical examination, and laboratory data are being collected (Table 3), with the frequency of measurement varying by group assignment, but at least at baseline, at one year and at the end of the trial. The weight measurement will be done always in

Table 1 Timetable of the IMOAP trial

\begin{tabular}{llll}
\hline Phase & No. of Months & Calendar Dates & Trial Activities \\
\hline 1 & 4 & $01 / 07-04 / 07$ & Protocol development. \\
2 & 8 & $05 / 07-12 / 07$ & $\begin{array}{l}\text { Acceptance to participate of Basic Health Areas. } \\
\text { Distribution and randomisation of the Basic Health Areas into both groups: Intervention/controls. } \\
3\end{array}$ \\
& 2 & $\begin{array}{l}\text { For those BHA that will visit the intervention groups, training of nursing staff and coordinating } \\
\text { the teams, creating templates and study protocols. }\end{array}$ \\
4 & 30 & $03 / 08-09 / 10$ & Main trial recruitment and follow-up \\
5 & 26 & $10 / 10-12-12$ & Follow-up only \\
6 & 4 & $12 / 12-04 / 13$ & Analysis and reporting \\
\hline
\end{tabular}

Table 2 Inclusion and exclusion criteria

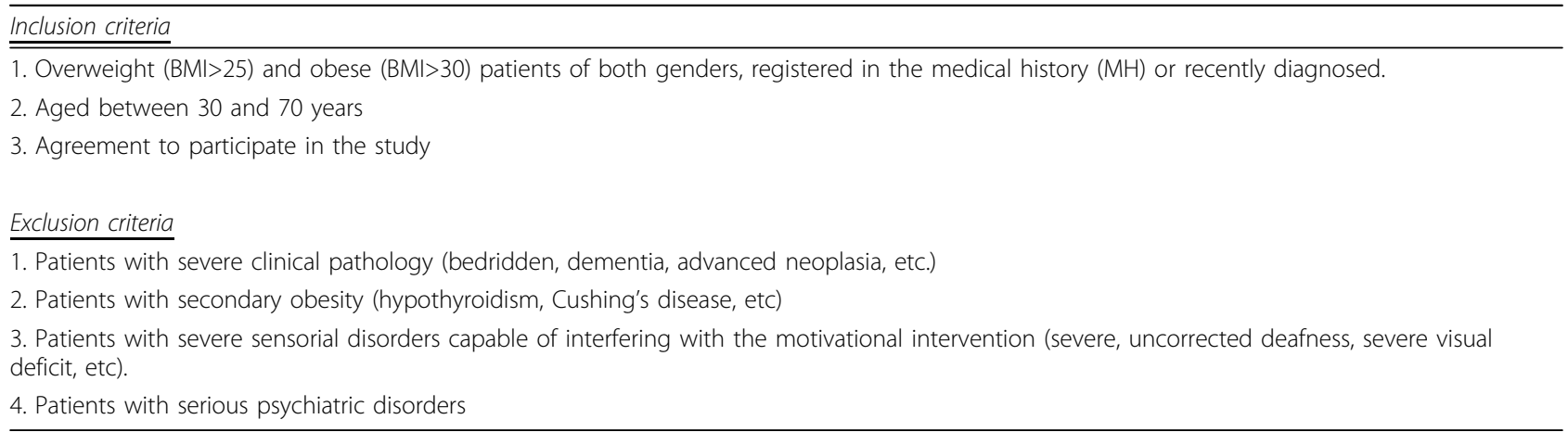




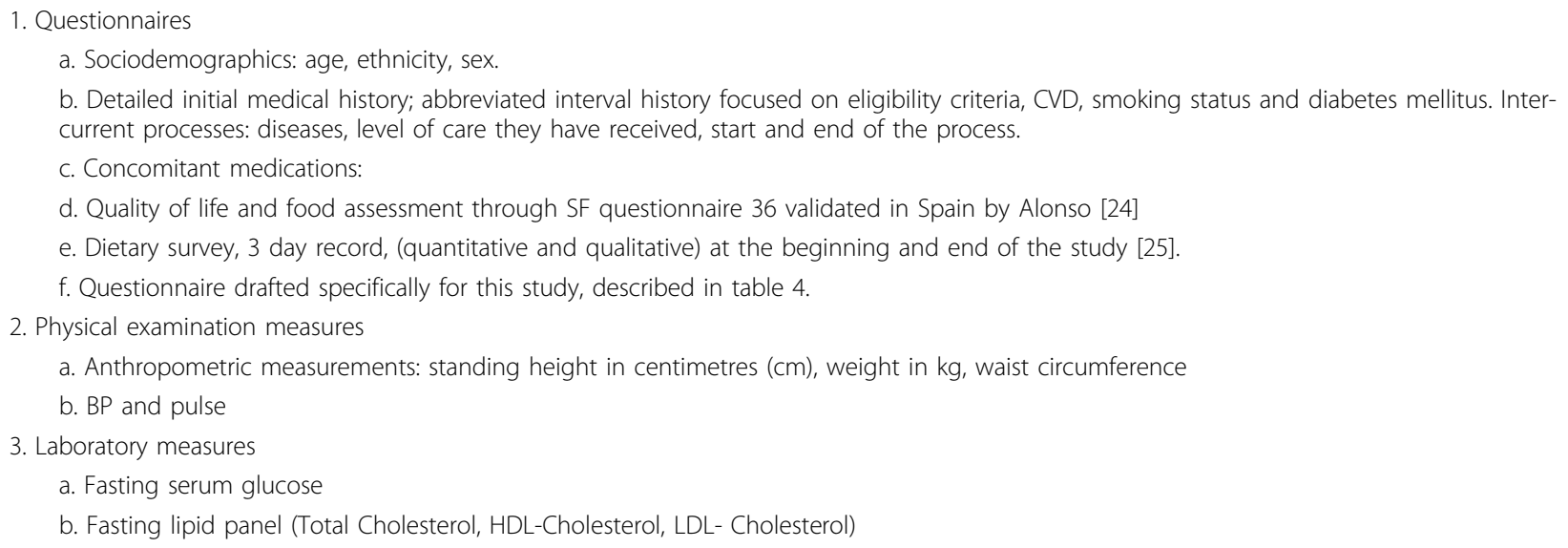

the same conditions (the patient wearing underwear only, barefoot, and at the same time of day). Body Mass Index (BMI) will be calculated as: Weight in kilos divided by height in square metres $\mathrm{W}(\mathrm{kg}) / \mathrm{H}(\mathrm{m} 2)$. Waist measurement will be defined as the midline between the edge of the lowest rib and the iliac crest alongside the anterosuperior iliac spine, in $\mathrm{cm}$. The cardiovascular risk factors will also be assessed: Hypertension will be defined as either blood pressure readings of above 140/90 on three occasions, (in diabetics, above 130/80); or patients receiving treatment for hypertension or with a clinical diagnosis of hypertension; Diabetes Mellitus: By case history or two prandial glycaemia readings > $126 \mathrm{mg} / \mathrm{dl}$; -Smoking: packets year.

Quality of life and food assessment through SF questionnaire 36 validated in Spain by Alonso [24], and dietary survey, 3 day record, (quantitative and qualitative) at the beginning and end of the study [25].

A questionnaire, drafted specifically for this study, and administered by the participating nurse, gathers the variables mentioned.

\section{Outcomes}

The primary endpoint for the IMOAP is to assess whether the efficacy of the healthcare professionals' usual practices, together with a motivational group intervention (delivered by a nurse trained by an expert psychologist), is more effective than an isolated traditional intervention on weight loss and its maintenance in overweight and obese patients.

This will be calculated as the percentage of patients reducing their weight by $5 \%$ and maintenance over time. The strategies for facing change and working in the groups [26-28] consist in providing information and practical advice on modifying eating habits, starting or increasing regular physical activity, lifestyle changes, functioning of the metabolism, management of the obesity and its complications, smoking as a cardiovascular risk factor, food diary, shopping methods and, finally, the number of calories to ingest.

\section{Formation of the patient groups}

Groups will be made up according to the following criteria: mixed, women and men, aged between 30 and 70 years, and a maximum 15 and minimum 7 members per group. Each nurse could manage 3 different groups (1 per month). The random assignment of the intervention will be done at the primary care Basic Health Areas (BHA), in L'Hospitalet de Llobregat, neighbouring areas and Barcelona city. Two groups will be formed in separate centres, one of which will receive the motivational group intervention (intervention group) and the other the standard treatment (control group). To prevent possible bias, the BHA located in the same building will be assigned to the same group (control or intervention). The participating healthcare professional (nurse) will select the first two patients with visits during the pre-established recruitment period, who met the study criteria.

\section{Intervention control group}

Participants will follow the usual intervention, according to the protocols in each centre, as it is described elsewhere [8]. The visits will be done every 3 months, including advice on life-style changes, physical exercise, hypo caloric diet, containing 1,200-1,500 kcal and anthrometric measurements (weight, height and waist perimeter). Follow up of blood tests by a healthcare professional will be done at the beginning, at one year and at the end of the study. In additional file 1 it is described the content of their visits.

\section{Motivational intervention in the intervention group}

Participants will follow the usual intervention, the same as in the control group, plus a group motivational intervention every 15 days, at the initial weeks 1 and 12 of the intervention, following the LEARN (Lifestyle, 
Exercise, Attitudes, relationships and Nutrition) programme [12] and then monthly at weeks 13 and 32, following the instructions of the Weight Maintenance Survival Guide programme [13]. Each session would last for one hour, for a 26 month follow up period, with a total of 32 interventions, as described in Table 4. Request for blood test at the start, at one year and at the end (3-year study duration). In additional file 2 it is described contents of the visit.

\section{Objectives of the psychological support}

Table 5 describes the main objectives proposed for the interventional group, aimed to facilitate the awareness and compliance with a series of requirements for

\section{Table 432 group sessions of the intervention}

In sessions 1 to 4 (fortnightly) we should raise awareness among the patients of the benefits of changing their habits, which will allow us to move from the "pre-contemplation" to the "contemplation" stage.

To do this we must provide them with ample information about the benefits of change, the recommended diets which will be dealt with individually with the nurse or doctor, physical exercise, etc.

This will be reinforced with the instructions given to individuals.

1. We will explore their fears, earlier failures, worries and difficulties that prevent them from taking the decision.

2. We will help sort out their doubts about unhealthy behaviour or habits to encourage life style changes towards a healthier life.

3. We will give them the tools they need to face situations where their usual strategies have failed.

4. We will encourage the patient to move towards the desire to change, attempting to help them recognise and take care of their present and future problems and strengthening their perception of the effects.

5. We will work on the patients' resistance.

In sessions 5 to 12 (fortnightly) we will have dispelled the patients' doubts and they will feel motivated to make a change to healthy habits and be committed to continuing with the programme.

We will then move into the "determination" stage

1. Reinforce the patient's self-motivational affirmations.

2. Point out the positive and negative aspects of the behaviour to suppress, the old and the new to be acquired.

3. Elaborate on these by asking for examples, clarifying the how, when, why...

4. Use extremes and image the best and worst results of the changes as well as their possible consequences.

5. Look backwards and/or forwards. Visualise with the patient what it was like before and how he/she thinks, he/she is going to feel once he/ she has given up this unhealthy habit.

6. Explore the feelings associated with the change (fear, anxiety, etc)

7. Explore if he has help and support from a partner/family.

8. Strengthen the active role the patient has in the change.

9. Understand the resistance to change.

10. Help develop strategies.

11. Develop a joint action plan

12. Combat feelings of loss caused by the change.

In sessions 13 to 32 (monthly) work with "changes" and "maintenance".

1. Bolster the capacity to change

2. Encourage the patients to give their own reasons.

3. Increase the consciousness towards change.

4. Understand the stress these changes in habits cause in the patients

5. Reinforce the benefits of change.

6. Bolster self-efficacy.

7. Support the changes.

8. Boost each member's capacity to make a change.

9. Understand the patients' emotions and thoughts.

10. Give empathetic responses.

11. Assist with the expression of feelings and emotions.

12. Prevent relapses through exploration

13. Identify risky situations and find strategies for dealing with them.

14. Support the work and efforts made and the benefits of change and maintenance of their decision.

From 1 to 12 , fortnightly sessions, from 13 to 32 , monthly sessions. 


\section{Table 5 Objectives of the physcological support}

-Give patients the opportunity to explain their difficulties, to achieve the
required objectives.
-Share their experiences and feelings with one another from their
group team.
-Enable the appearance and elaboration on the anxiety that arises with
lifestyle changes.
- Reinforce the changes made.
-Explain the benefits of these new attitudes.
- Clear up any doubts.
- Induce shared positive reinforcement.

lifestyle changes that will reinforce the medical follow up by creating intervention groups with psychological support to be conducted by nursing staff (previously trained by expert psychologists), [26,27]:

The Stages through which the patient passes before taking the decision to change his or her habits, following the Prochaska model [29], are described in Table 6.

\section{Sample size calculation}

The number of subjects necessary to divide into two independent groups has been calculated. With the standard intervention, a weight reduction of $5 \%$ of weight is expected (P1) $[30,31]$. It was predicted that the experimental intervention would lead to $75 \%$ of the patients reducing their weight by $5 \%$. It will be assumed an alpha risk of 0.05 (bilateral hypothesis) and a beta risk of 0.20 (a potential $80 \%$ ). If the interventions will be assigned individually, in other words, per patient, the number of patients in each group would be 328 (756 in total). If we assume a percentage loss of $20 \%$ and apply a correction according to the formula $\mathrm{Na}=\mathrm{N}[1 / 1-\mathrm{R})]$ where $\mathrm{N}$ is the theoretical number of subjects, $\mathrm{Na}$ is the corrected number of subjects and $\mathrm{R}$ is the expected proportion of loss, a total of 946 patients would be necessary. Given that the assignment of the interventions will be done by BHA, we had to increase the sample size because of the design effect [28]; if 24 BHA (clusters) were to participate, 12 per type of information, it would be $\mathrm{K}=[\mathrm{m}(1-\mathrm{CCI})] /[\mathrm{Z}-(\mathrm{CCI} \times \mathrm{m})]$ where $\mathrm{K}=$ number of subjects per cluster, $\mathrm{m}=473$ patients per intervention,
$\mathrm{Z}=$ number of clusters per type of intervention $=12$ and ICC $=$ intra-class correlation coefficient. We assumed that the basic ICC for the percentage of obese patients who would reduce their weight by $5 \%$ was 0.005 . The number of patients in each BHA (Cluster) would be 50.50 subjects $\times 12 \mathrm{BHA}=600$ patients per arm or type of intervention. 600 subjects $\times 2$ interventions $=$ a total of 1,200 patients.

\section{Statistical analysis}

A descriptive statistical analysis will be made according to the variables. For the quantitative variables, using the mean and standard deviation, for the qualitative ones, proportions will be used. The data analysis will include an evaluation of the initial comparability of the patients in the two types of intervention using bivariate techniques: The Chi-Square for the proportions and, in the case of the mean, the Student's t-distribution or its nonparametric equivalent when necessary, by point estimation with a confidence interval of $95 \%$.

The hypothesis to compare will be the null hypothesis, defined as equal efficacy of the usual and experimental interventions (both interventions achieved a weight loss of $5 \%$ in the same proportion of patients). The possible difference in efficacy between the interventions will be carried out through an analysis based on the individual values of the patients using multilevel statistical techniques [32].

\section{Discussion}

Overweight and obesity, serious and growing health problems, are not receiving the attention they deserve from primary care practitioners. An additional problem related to weight loss, if achieved, is its maintenance.

The study IMOAP analyses the management of overweight and obesity, in a group motivational intervention, managed by a nurse trained by an expert psychologist, in addition to usual practice, to see if this intervention is more efficient than the latter alone in the treatment of overweight and obesity in relation to percentage weight loss and maintenance. Also, if so, if it would it be possible to reduce the prevalence of classic and emerging cardiovascular risk factors that are related to

\section{Table 6 Stages in the intervention group}

\begin{tabular}{ll}
$\begin{array}{l}\text { A) Pre- } \\
\text { contemplation }\end{array}$ & $\begin{array}{l}\text { 1. Give the patient plenty of advice 2. Guide the patient in relation to the programme 3. Get commitment through the } \\
\text { motivational interview. 4. Evaluate the willingness and motivation to make changes. }\end{array}$ \\
\hline B) Contemplation & $\begin{array}{l}\text { 1. Evaluate willingness and motivation to make the changes 2. Get a realistic commitment through the motivational interview } \\
\text { 3. Reach an agreed decision to change behaviour and habits. }\end{array}$ \\
\begin{tabular}{ll} 
C) Preparation for & 1. Create an action plan within the group, adapting this to individual possibilities 2. Invite the family to collaborate. \\
action & $\begin{array}{ll}\text { 1. Introduce initiation of prevention of relapses during the group sessions. } 2 . \text { Introduce advice, educational activities about } \\
\text { healthy eating habits and smoking. 3. Include reinforcement for achievements. }\end{array}$ \\
\hline E) Maintenance & $\begin{array}{l}\text { 1. Introduce maintenance of prevention of relapses during the group sessions 2. Maintain the reinforcement for the } \\
\text { achievements made, highlighting the health benefits. }\end{array}$
\end{tabular}
\end{tabular}


overweight and obesity, and, in consequence, cardiovascular conditions.

The results of IMOAP trial should provide substantial direction regarding weight loss management at a primary care, and it could be introduced as a basic treatment tool for overweight and obese patients.

\section{Additional file 1: Control definite}

Additional file 2: Intervention

\section{Acknowledgements}

Supported by grants of 'Fondo de Investigaciones Sanitarias de la Seguridad Social, FIS (PI 070087). We thank all participating GPs for their cooperation, Ferran Flor for statistical advice and Institut Català de la Salut, for the collaboration in the laboratory analysis. We also want to thank to the investigators participant in the IMOAP trial:

Àrea Bàsica Salut (ABS) Florida Sud (L'Hospitalet de Llobregat - Barcelona): Juan José Rodríguez Cristóbal, José Ma Pérez Santos, Ma José González Burguillos*, Margarita Solanes Casas, MaCarmen Esparrach Casasses, Ana Ma Diez Tino, Marta Delclos Baulies, Elida Quillama Torres. ABS Florida Nord: Ma Del Carmen Mpa Sifuko, Carmen Morillo Godoy*, Teresa Gonzalez Nogales. ABS Bellvitge: Montse Blanco Rodriguez*, Gemma Luna Redondo, Adela Gonzalez Sierra, Trinidad Mejías Serrano, Oscar Sanchez Soro, Jorge Fernandez Ruiz, Eugenia Herrador Delso, Begoña Barnés Sánchez, Anna Comabella Cueco, Teresa Ruso Bernardo, Margarida Guino Royo, Yolanda Ginés Sánchez, ABS Sta Eulàlia Nord: Conrada Benitez Saiz, Fuensanta Mesa Aranda, Remedios Montes Velayos, Concepción Gonzalez Perez, Antonio Gomez Navarro, María Ramos Sanchez, Mònica Cano Lopez, Sandra Laborda Lopez, Isabel Gavin Blasco*, Carmen Lopez Sanchez, Eva Mon López, Aurora López Galán, Ma Carmen Muñoz Duque, Fina Arroyo Blesa. ABS Sta Eulàlia Sud: Mercedes Escudero Hernandez, Irene Pardo Escudero, Marife Alvarez Rodriguez, Bartolomé Rodriguez Lozano, Antonio Aranta Diaz. ABS St. Josep: Vicky Cabré Aguilar, Enric García Gomila, Roser Llort Rañe, Ana María Gil Colome, Julia Mena Sánchez, Mercedes Bielsa Alquezar, Raul Miguel Capillas Perez ${ }^{*}$. ABS Torrassa: Mercè Aliaga Ugarte, Rosario Fernandez Perez, Maria Isabel Muñoz Castanedo*, Montserrat Peraferrer Puigpelet, Carme Llorens Martinez, Miriam Montserrat Vinals, Ma Victòria Gomez Moral, Sacri Gutierrez Mesa. ABS Can Serra: Eduvigis Abril Escusa*, Almudena Gonzalez Casado, Montserrat Pérez Gañan, Ma Isabel García Villaplana, Magdalena Ortilles Tejera, Ágata Sala Sastre, Ma Dolores Leon Varo. ABS Gornal: Ma Carmen Gonzalez Sanchez, Rosa Gutierrez Lengua*. ABS Centre: Neus Lopez Ojeda*, Concepción Torralba Casado. ABS Pubilla Casas: Leonor Blasco Villanueva, Anna Gasol Farga, Montserrat Comelles Villalba, Carmen Contreras García*, Araceli Monge Escribano, Rosa Mas de Miguel Pérez, Isabel Ortega Abarca, Sonia Martínez Carmona, Rosa Gonzalez Diaz, Anna de Mon er de Castellano, Montserrat Bonfill Gavaldà, Rosalia Santesmases Masana, Eva Beltran. ABS Martí Julià (Cornellà de Llobregat - Barcelona): Angeles Toledano Perez, Alicia Rodríguez Pérez, MaDolores Rodriguez Magallanes*, Cinta Boix Cervera, Alicia Rodriguez Perez, Gloria Mercè Martorell, Manuel Baullon Rodríguez. ABS El Plà (St Feliu de Llobregat - Barcelona): Montserrat Sanchez*, Linarejos Jurado Vergara, Elena López Pérez, Ma Isabel Plaza Vicente. ABS Verdum (Barcelona): Glòria Tintoré Jiménez-Fortín*, Ma Engracia Valbuena, Yolanda Espinosa. ABS Prosperitat: Pilar Tarragó Espí, Ma Carmen Lamuedra Martínez; Juan Ramón Morón Bermejo, Amparo Bonet Bernabeu, Francisca Benavides*, Cristina Martín Sierra, Antonio Botey Serrano, Mónica Castro Pérez, Vicenta Estrada Mir, Antonia Ferre Codina, Rosana Coma. ABS Porta: Rosa Mené, Lidia Pujol Ramírez, Ma Engracia Aliguer Masramon, Montserrat Piñeiro Casaus, Teresa Giró Molmer. ABS Dr. Carles Ribas: Susana Morgade Gonzalez, Manuel Mendez Fernandez, Ma Rosario Madico Cerezo, Ramona Ortiz Secanell, Mercedes Liroz Navarro*, Gemma Capdevila Fogués, Gemma Roig i Ribas, Ma Jesús Valderas Sanchez. ABS Via Roma: Lydia Riba Bellera, Carmen Ubierna Gomez, Montse Roc Laborda, Marisol Rilova Perez, Maria José Morro Vevel, Anna Pérez Alberti, Ma Teresa Isidro Barbero, Teresa Serrano Demarco, Montserrat Medina Sacristan*, Guadalupe Fernández Esteve. ABS Universitat: Elisabeth Fontoba Nadal*, Luis Malvas Garcia, Marisa Torres Segura, Enric Pons Segales, Anna Manzanares Janini, Francesca Pablo Gil. ABS St Elies: Ma
Jesús Freixas Pascual*, Ma Rosina Crespo López, Ma José Borrell Mestre, Ma Esther Calero Molina, Silvia Gonzalez Rodríguez. ABS St. Antoni: Ma Concepción López Canfranc, Ma Emilia Velasco Vicente, Ma Teresa Fuertes Rodríguez, Montse Bosc, Àngels Arévalo Garcia, Ma Antonia Viloca Llobet, Ana Sánchez Alvarez, lluminada Perea Martinez, Julia T Mayta Taica, Charo Fuentes Roldan, Ma Antonia Cuesta Pipson, Gloria Paris Puigcerver, Ma Antonia Fernández, Isabel Ginés. ABS Vallcarca: David Garcia Bonias, Artur Daleo i Pibernat, Miriam Payan Cruz, Antoni Blasco Trabado, Maite Alvarez Castella, Esther Llauradó Sanclemente, Marga Mendez-Aguirre Guitian, Rosa Ma Yrla Figueras, Àngels Ballester Adell, Manuel Campiñez Navarro, Isabel Martínez Pascual, Esperanza Palacios Teruel, Nieves Barragán Brun, Palmira Villafuerte Navarro, Rosario Jiménez Leal, Rosario Corral Antón, Oscar Rochera López, Remedios Martin Alvarez, Yolanda Gomez Escudero, Ma Mercedes Garcia Fuentes. ABS Rec Comptal - Casc Antic: Montserrat Alegret *, Mireia Sánchez Zaragoza, Amparo Romera Cabezas, Lilia Villagrasa Romerales, Teresa Benítez Camacho, Montserrat Ventura Albadalejo, Dolores Marín Perales, Magda Elías Hernández, Rosa Solé Sancho. * main investigator.

\section{Author details}

${ }^{1}$ Medicina, Area Básica Salud Florida Sud, Parc dels Ocellets, L'Hospitalet del Llobregat, Barcelona, Spain. ${ }^{2}$ Departamento de Medicina, Hospital de Igualada, Barcelona, Spain. ${ }^{3}$ Institut Català de Ciències Cardiovasculars, Centre superior d'Investigacions Científiques, Barcelona, Spain. ${ }^{4}$ Departament mèdic, Solvay Pharma, Barcelona, Spain. ${ }^{5}$ Unitat de Salut Mental Collblanc,

L'Hospitalet del Llobregat, Barcelona, Spain. 'Eaboratorio Clínico L'Hospitalet. Institut Català de la Salut, Centre Assistència Primària Just Oliveras, L'Hospitalet de Llobregat, Barcelona, Spain. ${ }^{7}$ Area bàsica de la Salut Rio de Janeiro, Barcelona, Spain. ${ }^{8}$ Hospital de Viladecans, Viladecans, Barcelona, Spain.

\section{Authors' contributions}

JJRC formulated the research question, designed the study and supervised its conduct together with JPR, CAV and JPS. AML has been involved in drafting the manuscript. FRC, FBM, PMM, MJGB, MDB, DBF and EQT have monitored the nurses. All the authors approved the final manuscript.

\section{Competing interests}

AML acts as a scientific advisor for Solvay Pharma.

All other authors declare that they have no competing interest.

\section{Received: 5 September 2009 Accepted: 18 March 2010}

Published: 18 March 2010

\section{References}

1. Obesity: preventing and managing the global epidemic. Report of a WHO consultation. Technical report series n. ${ }^{\circ} 894$ Geneva WHO 2000.

2. National Institutes of Health: National Heart, Lung and Blood Institute. Clinical Guidelines on the identification, evaluation and treatment of overweight and obesity in adults. The evidence report. Bethesda 1999.

3. Bonow RO, Eckel RH: Diet, obesity, and cardiovascular risk. $N$ Engl J Med 2003, 348:2057-8.

4. Ridker PM, Stampfer MJ, Rifai N: Novel risk factors for systemic atherosclerosis: a comparison of C-reactive protein, fibrinogen, homocysteine, lipoprotein(a), and standard cholesterol screening as predictors of peripheral arterial disease. JAMA 2001, 285:2481-5.

5. Cañizo FJ, Aguilar M, Carral F, Conget I, Costa A, Esteve E: Diabetes Mellitus tipo 2 y factores de riesgo cardiovascular. Nilo industria gráfica S.A 2003, 103-104.

6. Dotevall A, Johansson S, Wilhelmsen L: Association between fibrinogen and other risk factors for cardiovascular disease in men and women. Results from the Göteborg MONICA survey 1985. Ann Epidemiol 1994, 4:369-74.

7. Peeters A, Barendregt JJ, Willekens F, Mackenbach JP, Al Mamun A, Bonneux L, NEDCOM, the Netherlands Epidemiology and Demography Compression of Morbidity Research Group: Obesity in adulthood and its consequences for life expectancy: A life-table file analysis. Ann Intern Med 2003, 138:24-32.

8. Aranceta J, Foz M, Gil B, Jover E, Mantilla T, Millán J, Monereo S, Moreno B: Documento de consenso: Obesidad y riesgo cardiovascular. Clin Invest Arterioscl 2003, 15:196-233. 
9. Gutiérrez-Fisac JL, Banegas-Banegas JR, Rodríguez Artalejo F, Regidor E: Increasing prevalence of overweight and obesity among Spanish adults, 1987-1997. Int J Obesity 2000, 24:1677-82.

10. Vázquez R, López JMa: Obesidad: La epidemia del siglo XXI. Rev Esp Econ Sal 2002, 1:34-42.

11. Sociedad Española para el Estudio de la Obesidad (SEEDO): Consenso SEEDO'2000 para la evaluación del sobrepeso y la obesidad y el establecimiento de criterios de intervención terapéutica. Med Clin (Barc) 2000, 115:587-597.

12. Brownell KD, ed: The LEARN program for weight control. Dallas: American Health Publishing, 71998.

13. Brownell KD, Rodin J: The weight maintenance survival guide. Dallas: Brownell\&Hager 1990.

14. Gortmaker SL, Must A, Perrin JM: Social and economic consequences of overweigh in adolescence and young adulthood. New Engl J Med 1993, 329:1008-12.

15. Barr SI, Yarker KV, Levy-Milne R, Chapman GE: Canadian dietitians' views and practices regarding obesity and weight management. J Hum Nutr Diet 2004, 17:503-12.

16. Steptoe A, Kerry S, Rink E, Hilton S: The impact of behavioral counseling on stage of change in fat intake, physical activity, and cigarette smoking in adults at increased risk of coronary heart disease. Am J Public Health 2001, 91:265-9.

17. Wadden TA, Berkowitz RI, Womble LG, Sarwer DB, Phelan S, Cato RK, Hesson LA, Osei SY, Kaplan R, Stunkard AJ: Randomized Trial of Lifestyle Modification and Pharmacotherapy for Obesity. N Engl J Med 2005, 353:2111-20.

18. Shaw K, O'Rourke P, Del Mar C, Kenardy J: Intervenciones psicológicas para el sobrepeso o la obesidad (Revisión Cochrane). The Cochrane Library 2005, 4[http://www.update-software.com].

19. Duenas Herrero RM, Aleu Bover M, Gonzalez Tejon I, San Molina L, Salavert Jimenez J, Arranz Marti B: Impact of medical counseling to quit smoking during the process of dehabituation in patients with mental illness. Actas Esp Psiquiatr 2004, 32:287-92.

20. Wakefield M, Olver I, Whitford H, Rosenfeld E: Motivational interviewing as a smoking cessation intervention for patients with cancer: randomized controlled trial. Nurs Res 2004, 53:396-405.

21. McCambridge J, Strang J: The efficacy of single-session motivational interviewing in reducing drug consumption and perceptions of drugrelated risk and harm among young people: results from a multi-site cluster randomized trial. Addiction 2004, 99:39-52.

22. Burke BL, Arkowitz H, Menchola M: The efficacy of motivational interviewing: a meta-analysis of controlled clinical trials. J Consult Clin Psychol 2003, 71:843-61.

23. Lugoboni F, Quaglio G, Mezzelani P, Pajusco B, Casari R, Lechi A: Improving compliance in internal medicine: the motivational discussion. Ann Ital Med Int 2004, 19:155-62.

24. Alonso J, Regidor E, Barrio G, Prieto L, Rodríguez C, de la Fuente L: Valores poblacionales de referencia de la versión española del Cuestionario de Salud SF-36. Med Clin (Barc) 1998, 111:410-416.

25. Burke BSR: The diet history as a tool in research. J Am Diet Assoc 1947 23:1041-1046.

26. Bion WR: Experiencias en grupos. . Ed Piadós. Barcelona 1985.

27. Grinberg L, Langer M, Rodrigué E: Psicoterapia del grupo, Buenos Aires, 1961. Ed Paidós 1961.

28. Doyle M, Siegel R, Supe K: Stages of change and transitioning for adolescent patients with obesity and hypertension. Adv Chronic Kidney Dis 2006, 13:386-93.

29. Prochaska JO, Velicer WF, Rossi JS, Goldstein MG, Marcus BH, Rakowski W, Fiore C, Harlow LL, Redding CA, Rosenbloom D: Stages of change and decisional balance for 12 problems behaviors. Health Psichology 1994, 13:39-46.

30. Formiguera i Sala X: Moreno Esteban y el grupo de investigadores del Estudio OBESO. Rev Esp de Obesidad 2003, S1:10-19.

31. Omar RZ, Thompson SG: Analysis of a cluster randomised trial with binary outcome data using a multilevel model. Stat Med 2000, 19:2675-88.

32. Machin D, Campbell M, Fayers P, Pinol A: Sample Size Tables files for Clinical Studies Blackwell Science. Oxford 1997.

\section{Pre-publication history}

The pre-publication history for this paper can be accessed here:http://www. biomedcentral.com/1471-2296/11/23/prepub

doi:10.1186/1471-2296-11-23

Cite this article as: Rodríguez Cristóbal et al:: Group motivational intervention in overweight/obese patients in primary prevention of cardiovascular disease in the primary healthcare area. BMC Family

Practice 2010 11:23

\section{Submit your next manuscript to BioMed Central and take full advantage of:}

- Convenient online submission

- Thorough peer review

- No space constraints or color figure charges

- Immediate publication on acceptance

- Inclusion in PubMed, CAS, Scopus and Google Scholar

- Research which is freely available for redistribution

Submit your manuscript at www.biomedcentral.com/submit
C) Biomed Central 